\title{
Aminoguanidine cream ameliorates skin tissue microenvironment in diabetic rats
}

Ming Tian, Chun Qing, Yiwen Niu, Jiaoyun Dong, Xiaozan Cao, Fei Song, Xiaoyun Ji, Shuliang Lu

Shanghai Burns Institute, Rui Jin Hospital, Shanghai Jiao Tong University, School of Medicine, Shanghai, China

Submitted: 10 February 2014

Accepted: 7 June 2014

Arch Med Sci 2016; 12, 1: 179-187

DOI: 10.5114/aoms.2016.57595

Copyright $\odot 2016$ Termedia \& Banach

\section{Abstract}

Introduction: The aim of the study was to explore the effect of aminoguanidine cream on the skin tissue microenvironment in diabetic rats.

Material and methods: A total of 51 healthy male Sprague Dawley (SD) rats were randomly divided into three groups: the diabetes group $(n=18)$, the aminoguanidine group $(n=18)$ and the control group $(n=15)$. Rats in the diabetes group and aminoguanidine group were injected with $65 \mathrm{mg} /$ $\mathrm{kg}$ streptozotocin to induce the diabetes model, and in the control group with citrate buffer. After successful induction of diabetes, the back hair of all rats was stripped by barium sulfide, and the aminoguanidine group was treated with aminoguanidine cream using disinfected cotton swabs twice every day for 40 days, while the diabetes and control groups were treated with the cream matrix. The pathological changes of skin were observed by $\mathrm{HE}$ staining, while the content of inflammatory cytokines (TNF- $\alpha$, IL-8, ICAM and IL-1 $\alpha$ ) and the antioxidant indexes (T-AOC, GSH-PX, MPO MDA $\mathrm{H}_{2} \mathrm{O}_{2}$ ) were examined using commercial kits.

Results: After 40 days of treatment, the diabetes group manifested tissue lesions, whereas the aminoguanidine group seemed normal. Compared with the diabetes group, the content of inflammatory cytokines TNF- $\alpha$, IL-8, ICAM and IL-1 $\alpha$ was dramatically lower in the aminoguanidine group. T-AOC in all groups underwent dramatic changes and returned to normal finally. The activities of GSH-PX and MPO and content of $\mathrm{H}_{2} \mathrm{O}_{2}$ in the diabetes group were all higher than those in the aminoguanidine group.

Conclusions: Aminoguanidine may have a good systemic effect on alleviating the pathological changes of skin tissue in diabetic rats, which may be attributed to the regulation of GSH-PX, TNF- $\alpha$, IL-8, ICAM and IL- $1 \alpha$.

Key words: aminoguanidine, diabetic, skin tissue, oxidative stress, proinflammatory cytokines, streptozotocin.

\section{Introduction}

Diabetes mellitus (DM), a group of metabolic diseases with high blood sugar, is due to either the pancreas not producing enough insulin, or because cells of the body do not respond properly to the produced insulin [1]. The prevalence of diabetes is increasing every year worldwide, and in China, the number of diabetes patients is growing rapidly and has reached more than 92 million in the last decade. Generally, diabetic patients always suffer from various complications, such as chronic lower extremity skin ulcer, which affects about $15 \%$ of patients. The skin ulcer on the lower limb is known as a common complication for diabetes pa-

\author{
Corresponding author: \\ Shuliang Lu MD \\ Shanghai Burns Institute \\ Rui Jin Hospital \\ Shanghai Jiao Tong \\ University School of Medicine \\ Shanghai 200025, China \\ No. 197 Rui Jin Er Road \\ Shanghai 200025, China \\ Phone: +86-021-64370045- \\ 611001 \\ Fax: +86-021-64675394 \\ E-mail: \\ lushuliangrj@hotmail.com
}


tients and it greatly affects the quality of patients' life and works [2, 3]. The ulcer may even progress into lower limb ischemia, which is a serious event in diabetes patients and may lead to increased mortality and morbidity in this particular patient population [4]. However, there is still no effective treatment to fight against the complication. It has been reported that locally external application of a gentamicin-impregnated collagen sponge can shorten the wound healing duration in diabetic patients [5]. Therefore, the external application of a certain drug to prevent or treat lesions may be a simple, effective and safe approach for diabetic skin ulcer.

Aminoguanidine is a nucleophilic hydrazine compound, and the basic chemical structure is $\mathrm{HN}-\mathrm{NH}-\mathrm{C}-\mathrm{NH}$. Aminoguanidine has been indicated to have a protective effect on the passive avoidance learning and memory in streptozotocin-induced diabetic rats acting through regulation of apoptosis-related genes in the hippocampus [6]. Moreover, aminoguanidine has also been reported to influence the counter-torque force of bone implants in streptozotocin-induced diabetic rats [7] Aminoguanidine is suggested to be a safe drug for the treatment of diabetes complications at a dosage of $1 \mathrm{~g} / \mathrm{l}$ [8]. Research has shown that aminoguanidine can competitively bind to the early glycosylation products, generate an inactive substitute which would not cause protein cross-linking, and thereby inhibit the formation of advanced glycation end products (AGE) [9]. Aminoguanidine can promote wound healing in diabetes by blocking AGE deposition and improving the microenvironment [10]. Advanced glycation end products are a kind of irreversible glycation products, which can cause changes in cell function and structure, lesions and oxidative stress of skin tissue matrix, and further lead to delayed healing [11-13]. It has been reported that lower extremity ulcer is refractory, mainly due to the accumulation of AGE in skin tissue of diabetic patients $[14,15]$. Therefore, we speculate that materials which can reduce or inhibit the generation of AGE may have a therapeutic effect on the refractory complication. Moreover, aminoguanidine has been successfully applied in the treatment of many other diabetic complications, including diabetic nephropathy, atherosclerosis and other complications [8, 16-18]. However, studies involving the effect of aminoguanidine on trauma by improving the skin tissue microenvironment are relatively rare.

In the current study, we aimed to evaluate the effect of aminoguanidine in models of induced trauma after diabetes by detecting the AGE-related proinflammatory cytokines (tumor necrosis factor $\alpha-$ TNF- $\alpha$, interleukin 8 (IL-8), intercellular adhesion molecule (ICAM) and IL-1 $\alpha$ ) and oxi- dative stress factors (total antioxidant capacity (T-AOC), methane dicarboxylic aldehyde (MDA), myeloperoxidase (MPO), glutathione peroxidase (GSH-PX) and $\mathrm{H}_{2} \mathrm{O}_{2}$ ). We expect the study to supply new insights for the treatment of lower extremity skin ulcers in diabetic patients.

\section{Material and methods}

\section{Preparation of aminoguanidine cream}

The oil-in-water cream matrix was prepared by mixing a certain proportion reagents, including an oil phase $(100 \mathrm{~g} / \mathrm{ml}$ stearic acid, $12 \%$ liquid paraffin, $15 \mathrm{~g} / \mathrm{l}$ Vaseline, $15 \mathrm{~g} / \mathrm{l}$ lanolin, $50 \mathrm{~g} / \mathrm{l}$ isopropyl myristate) and a water phase (0.8\% glycerol, $0.1 \%$ nipagin alcohol, $0.2 \%$ triethanolamine). Then the aminoguanidine powder was gradually added to the cream matrix below $60^{\circ} \mathrm{C}$ to finish the aminoguanidine cream.

\section{Diabetic rat model and aminoguanidine treatment}

A total of 51 healthy male Sprague Dawley (SD) rats (weighing 240-270 g, about 7 weeks old) were provided by the experimental animal department of Fudan University in Shanghai, China. Then the SD rats were randomly divided into three groups: the diabetes group $(n=18)$, the aminoguanidine group $(n=18)$ and the control group $(n=15)$. The rats were fasted for about $16 \mathrm{~h}$ (5 p.m. -9 a.m.) before induction of diabetes as in previous studies $[19,20]$. The diabetes group and aminoguanidine group were intraperitoneally injected with $65 \mathrm{mg} / \mathrm{kg}$ streptozotocin (STZ, Sigma, USA) to induce diabetes. In detail, $4 \mathrm{mg} / \mathrm{ml} \mathrm{STZ}$ was dissolved in 0.05 M citrate buffer at $\mathrm{pH} 4.0-4.5$ $[21,22]$ to finally prepare the $10 \mathrm{ml}$ injection. The control group was injected with the same volume of citrate buffer. Blood glucose levels were detected using blood samples collected from the caudal vein by the GLUCOTREND 2 blood glucose detector (Roche company, USA), and weights of rats were measured using electronic scales once a week after injection. In the aminoguanidine group and diabetes group, successful induction of diabetes was determined by slowly increased weight, withered and yellow hair and elevation of blood glucose. All animal studies have been approved by China Ethics Committee and performed in accordance with the ethical standards. Rats were housed individually at $20-24^{\circ} \mathrm{C}$ with $40-60 \%$ relative humidity and a 12 h (7:00-19:00) light/dark cycle. They were fed with a standard laboratory diet and distilled water ad libitum during the experiment.

Six weeks after successful induction of diabetes, back hair of rats in all groups was stripped by barium sulfide, prepared using barium sulfide (35 g), flour (3 g) and talcum powder (35 g) dis- 
solved in $100 \mathrm{ml}$ water and tuned into a paste. In the aminoguanidine group, rats were smeared with aminoguanidine cream using disinfected cotton swabs twice every day (at 9: 00 a.m. and 16:00 p.m.) for 6 weeks, while in the diabetes group and normal control group, rats were only smeared with the cream matrix without aminoguanidine.

\section{Hematoxylin and eosin (HE) staining}

After successful induction of diabetes in SD rats, pathological changes of skin tissue were observed by HE staining using 4 randomly selected rats every 10 days. Skin tissues were extracted and prepared as described previously [23]. In brief, on days $10,20,30$ and 40 days after induction of diabetes, the animals were weighed and anesthetized with pentobarbital sodium $(40 \mathrm{mg} / \mathrm{kg}$, ip), followed by being affixed to the operating table. Then the wound was excised with a margin of $1 \mathrm{~cm}$ of healthy skin around the lesion, incising deeply into the fascia muscle. After collection of materials, the animals were sacrificed using an overdose of pentobarbital sodium. Therefore, after days 10, 20 and 30 days after induction of diabetes, there were respectively 39, 27 and 15 rats left.

The skin samples were then divided into 2 parts. One was taken for measurement of proinflammatory cytokines and oxidative stress factors after homogenate in 1:9 (V/V) normal saline; the other was fixed in $10 \%$ formalin solution for more than $24 \mathrm{~h}$, and then embedded in paraffin, and cut into $4 \mu \mathrm{m}$ thick sections, followed by $\mathrm{HE}$ staining with a standard procedure (performed by SunteamBio, China). The changes and inflammatory cell infiltration in skin tissues were observed under an Olympus AX70 microscope (Olympus, Tokyo, Japan).

\section{Liquid chip analysis of proinflammatory cytokines}

The expression of inflammatory cytokines TNF- $\alpha$, IL- 8, ICAM and IL- $1 \alpha$ in skin tissue was detected by liquid chip every 10 days. The reagents in liquid chip were purchased from Panomics Company (USA). The skin samples were first homogenized in the neutral buffer following the instructions, then centrifuged for $10 \mathrm{~min}$ at $1000 \mathrm{~g}$ to remove debris in samples. After that, the supernatants were ready for the following detection. The washing buffer was prepared according to the instructions, and then used to wash the well before and after addition of the antibody beads. After the standard samples and test samples were added into the wells, the wells were sealed with aluminum foil and incubated at $4^{\circ} \mathrm{C}$ overnight, followed by being washed with washing buffer three times. Then the detection antibody was added, and incubated for $30 \mathrm{~min}$ at room temperature, followed by washing with buffer 3 times again. Finally, the streptavidin-PE was added, incubated for $30 \mathrm{~min}$, and also washed three times. After that, the samples were added with reading buffer, and detected by the BioPlex200 system (Bio-Rad Laboratories, Inc., Hercules, CA).

\section{Analysis of oxidative stress}

The skin samples were homogenized with 9 volumes of normal saline, and the homogenate was used to detect by colorimetry the expression of oxidative stress factors such as the T-AOC, MDA, MPO, GSH-PX and $\mathrm{H}_{2} \mathrm{O}_{2}$. Before detection, the skin homogenate was diluted with 99 volumes of normal saline and then measured with a spectrophotometer (DU-65, Beckham, Germany) at $595 \mathrm{~nm}$ with $1 \mathrm{~cm}$ optical path. All the procedures were conducted following the instructions, and normal saline was used in the blank wells. Finally, the protein content was obtained according to the following formula: protein content $=$ (test OD - blank OD)/(standard OD - blank OD) $\times$ standard protein concentration $(0.563 \mathrm{mg}$ protein $/ \mathrm{ml})$ $x$ dilution multiple.

\section{Statistical analysis}

All data were expressed as mean \pm SD and analyzed using SPSS 13.0 (Chicago, IL, USA). The comparison among experimental groups was conducted with one-way ANOVA, while the multiple comparisons were performed using the LSD method. Value of $p<0.05$ was considered statistically significant.

\section{Results}

\section{Morphological changes in aminoguanidine treated skin tissues in diabetic rats}

As shown in Figure $1 \mathrm{~A}$, scaly epithelium and collagen fiber of skin tissue were normal, interstitial inflammatory reaction was not obvious and cutaneous appendages were visible in the control group during the whole experiment. However, after 10 days of treatment, scaly epithelium of skin tissue was slightly thinned in the diabetes group (Figure $1 \mathrm{~B}$ ), while it was mildly hyperplasic in the aminoguanidine group (Figure $1 \mathrm{C}$ ). After 20 days, scaly epithelium of skin tissue became thinner in the diabetes group (Figure $1 \mathrm{D}$ ), but it was mildly hyperplasic and became thick in the aminoguanidine group (Figure $1 \mathrm{E}$ ). As shown in Figure $1 \mathrm{~F}$, after 30 days of treatment, scaly epithelium of skin tissue slightly thickened in the diabetes group compared with 20 days; while in the aminoguanidine group (Figure $1 \mathrm{G}$ ) the morphol- 

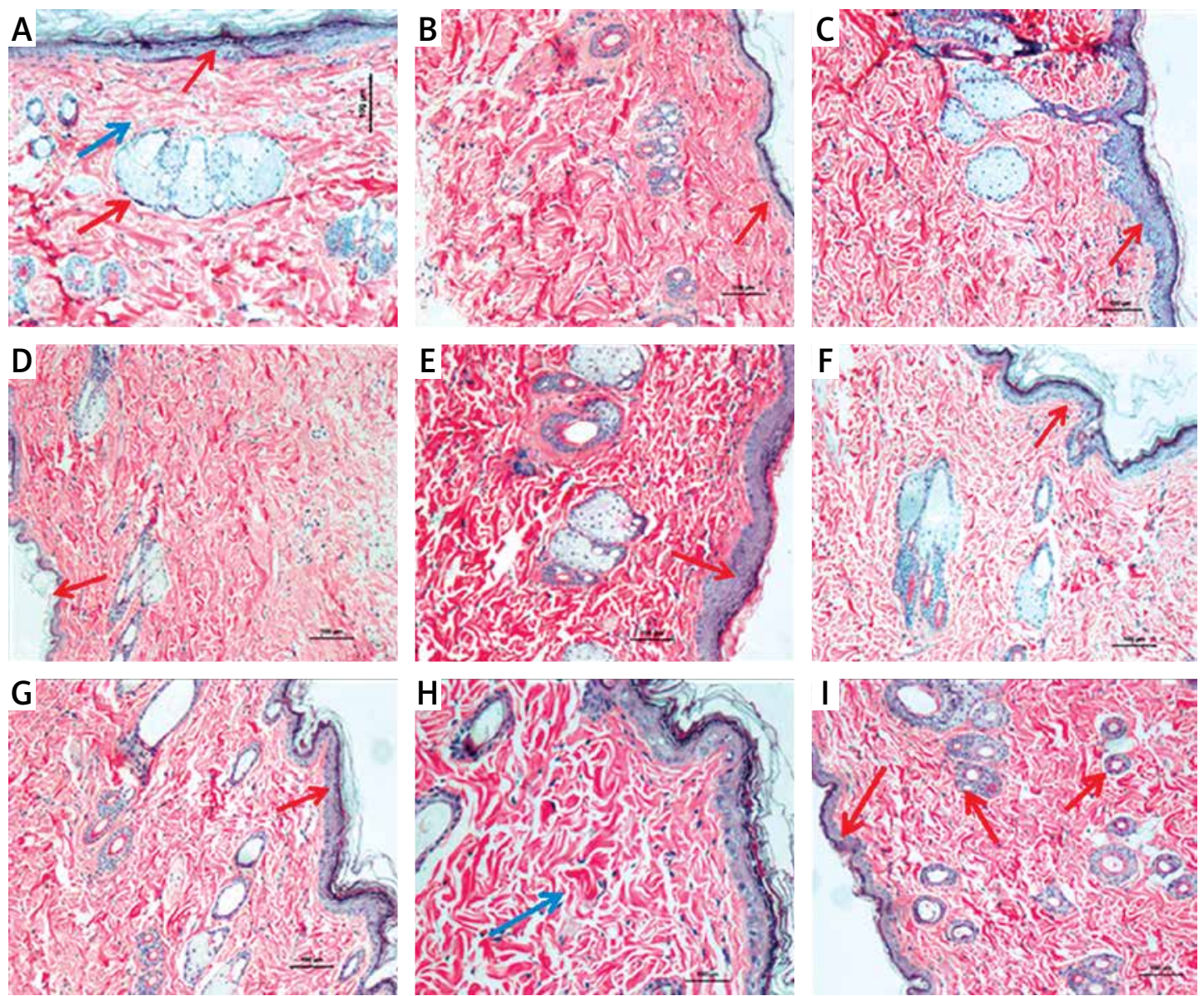

Figure 1. Pathological examination of rat skin tissues by HE staining (100x). During the experiment after diabetes induction, there were respectively $39,27,15$ rats left after days 10,20 and 30 . A - Control group; B, D, F, H - diabetic rat skin at 10 (B), 20 (D), 30 (F), 40 (H) days; C, E, G, I - aminoguanidine treated diabetic rat skin at 10 (C), $20(\mathrm{E}), 30(\mathrm{G}), 40$ (I) days. The red arrow points to the scaly epithelium, the blue arrow points to collagen fiber of skin tissue, and the dark red arrow points to the cutaneous appendages

ogy did not change compared with 20 days. After 40 days, scaly epithelium of skin tissue was still slightly thickened in the diabetes group and the collagen fiber became mildly hyaline, but the interstitial inflammatory response was negative and cutaneous appendages were visible (Figure $1 \mathrm{H}$ ). However, in the aminoguanidine group, scaly epithelium of skin tissue was mildly hyperplasic and became thick, collagen fiber was normal, interstitial inflammatory response was negative, cutaneous appendages were visible, and both hair follicles and sebaceous glands were proliferated (Figure $1 \mathrm{l}$ ).

\section{Effect of inflammatory cytokine in skin tissue} by using aminoguanidine in diabetic rats

As a result, the expression of $\mathrm{IL}-8$ in the diabetes group and the aminoguanidine group were sustained at a higher level than the control group in the first 20 days $(p<0.05)$. After 20 days, the expression level of IL-8 in the diabetes group and the aminoguanidine group began to decrease, especially in the aminoguanidine group, in which the
IL-8 level on the $40^{\text {th }}$ day was significantly lower than that on the $20^{\text {th }}$ day $(p<0.05)$, almost the same as in the control (Figure $2 \mathrm{~A}$ ).

As for TNF- $\alpha$, there was no significant difference between the diabetes group and the control group in the first 30 days, but the diabetes group showed a sharp increase on the $40^{\text {th }}$ day $(p<0.05)$. In the aminoguanidine group, the expression level of TNF- $\alpha$ was similar to the control group, and it decreased significantly compared with the diabetes group on the $40^{\text {th }}$ day $(p<0.05)$ (Figure $2 \mathrm{~B}$ ). The expression levels of $\mathrm{IL}-1 \alpha$ in the diabetes group and aminoguanidine group were both higher than that in the control group on the $20^{\text {th }}$ day and $30^{\text {th }}$ day ( $p<0.05$, Figure $2 \mathrm{C}$ ).

Moreover, the IL- $1 \alpha$ level on the $40^{\text {th }}$ day in the diabetes group was higher than that in the control group and aminoguanidine group; also, the IL-1 $\alpha$ level on the $30^{\text {th }}$ day in the aminoguanidine group was significantly higher than that on the $40^{\text {th }}$ day $(p<0.05$, Figure $2 \mathrm{C})$.

Finally, the expression level of ICAM in the aminoguanidine group showed dramatic fluctuations during the 40 days, and was significantly lower 
A

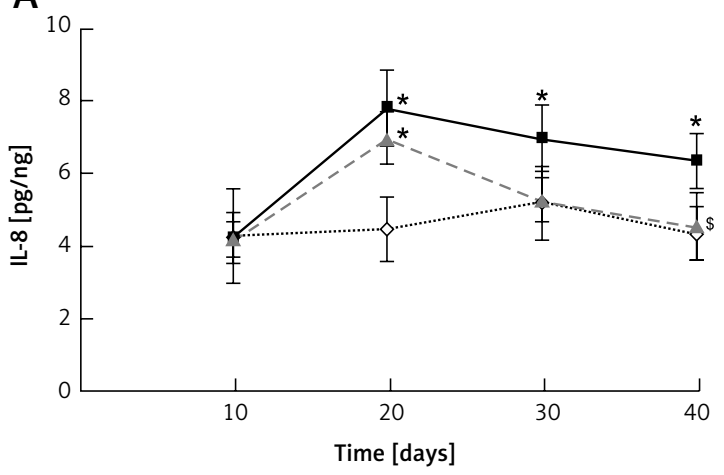

C

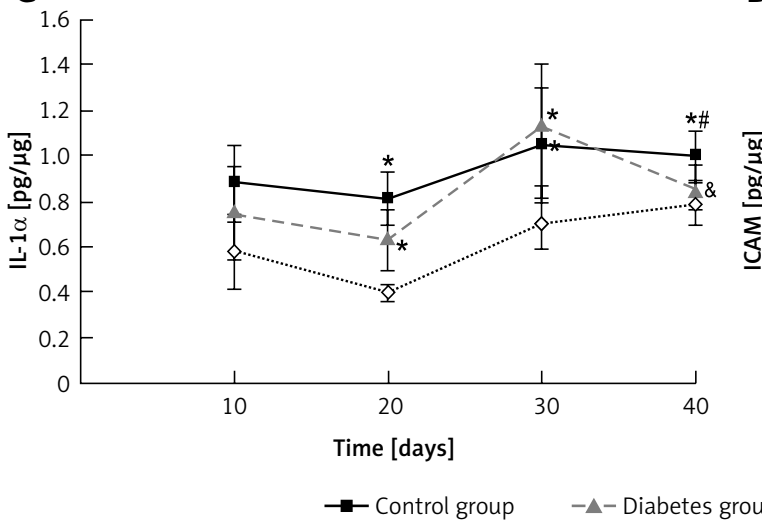

B

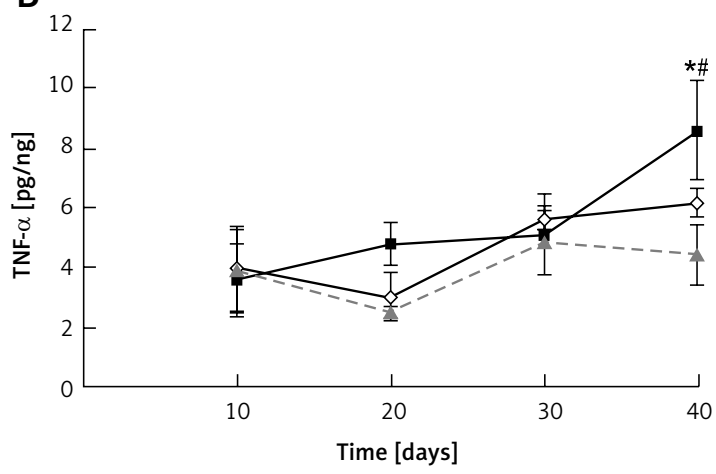

D

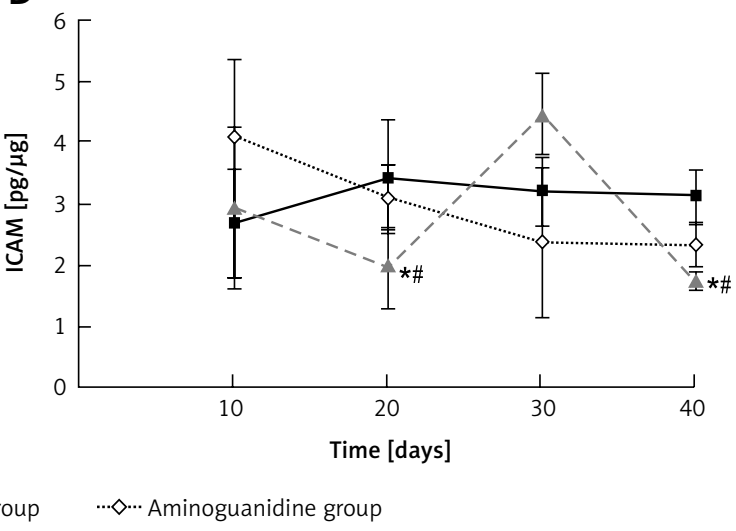

Figure 2. Expression levels of inflammatory cytokines in three groups of rats at different times (10, 20, 30, 40 days). A - IL-8, B - TNF- $\alpha$, C - IL-12, D - ICAM

${ }^{*} P<0.05$ vs. control group; ${ }^{*} p<0.05$ vs. aminoguanidine group; ${ }^{s} p<0.05, I L-8$ level on $40^{\text {th }}$ day vs. that on $20^{\text {th }}$ day; ${ }^{*} p<0.05, I L-1 \alpha$ level on $40^{\text {th }}$ day vs. that on $30^{\text {th }}$ day.

than that in normal and diabetes groups on both the $20^{\text {th }}$ and $40^{\text {th }}$ days ( $p<0.05$, Figure $2 \mathrm{D}$ ).

\section{Effect of oxidative stress in skin tissue by using aminoguanidine in diabetic rats}

The expression of oxidative stress factors (T-AOC, MDA, MPO, GSH-PX, $\mathrm{H}_{2} \mathrm{O}_{2}$ ) was also detected in this study. As a result, the T-AOC in both the diabetes group and the aminoguanidine group was in a higher state on the $10^{\text {th }}$ day, while on the $20^{\text {th }}$ day, both were significantly lower than the control group ( $p<0.05$, Figure $3 A)$. On the $30^{\text {th }}$ day, the T-AOC in the diabetes group decreased to the nadir during the whole experiment, which was significantly lower than that in the control and aminoguanidine groups ( $p<0.05$, Figure $3 \mathrm{~A})$.

The content of GSH-PX in the diabetes group remained in a stage of growth and was obviously higher than that in the control group from the $20^{\text {th }}$ day $(p<0.05)$, while in the aminoguanidine group, the GSH-PX level was markedly lower on the $10^{\text {th }}$ day and significantly higher on the $30^{\text {th }}$ day than that in the control group ( $p<0.05$, Figure $3 \mathrm{~B}$ ). Another factor, $\mathrm{H}_{2} \mathrm{O}_{2}$, began to increase after 30 days in the diabetes group, while it started to decline in the aminoguanidine group, which had a peak on the $20^{\text {th }}$ day (Figure $3 \mathrm{C}$ ). The MDA expression level in the diabetes group was significant lower than the control group ( $p<0.05)$. The level of MDA in the aminoguanidine group rapidly decreased after 20 days, but it apparently rose after 30 days and the difference was evident compared with the diabetes group $(p<0.05)$ (Figure $3 \mathrm{D})$. According to $M P O$, it reached a peak on the $40^{\text {th }}$ day in the diabetes group. However, it kept at a relatively stable state in the aminoguanidine group, which was similar to the control group on the $40^{\text {th }}$ day (Figure $3 \mathrm{E}$ ).

\section{Discussion}

Diabetes patients are easily hurt on account of the dull feeling caused by peripheral neuropathy. The peripheral neuropathy in diabetes has been reported to have an association with the APOE gene polymorphisms, although there is no robust evidence for the association [4]. Moreover, the trauma of diabetes patients is usually hard to heal because the high glucose environment of the related cells is a better substrate for bacterial reproduction. Numerous studies have demonstrated that the intractable trauma of diabetes is related to the deposition of AGE. Thus, we speculate that the trauma will heal more quickly if the for- 
A

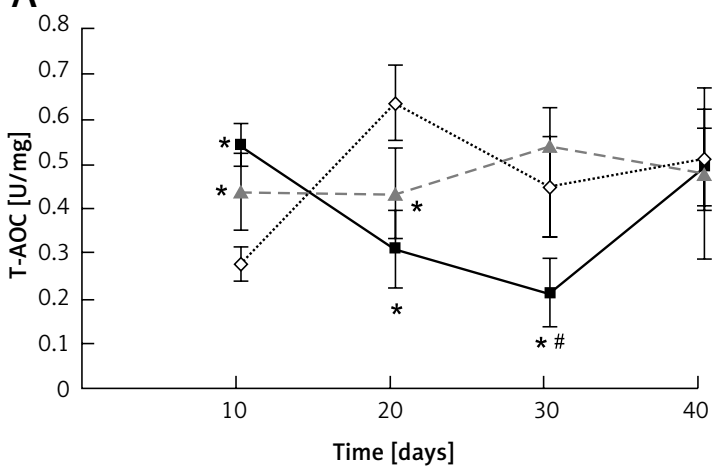

C

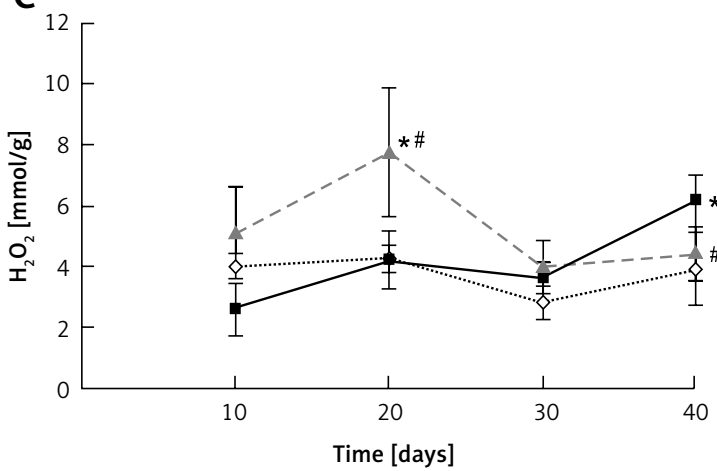

E

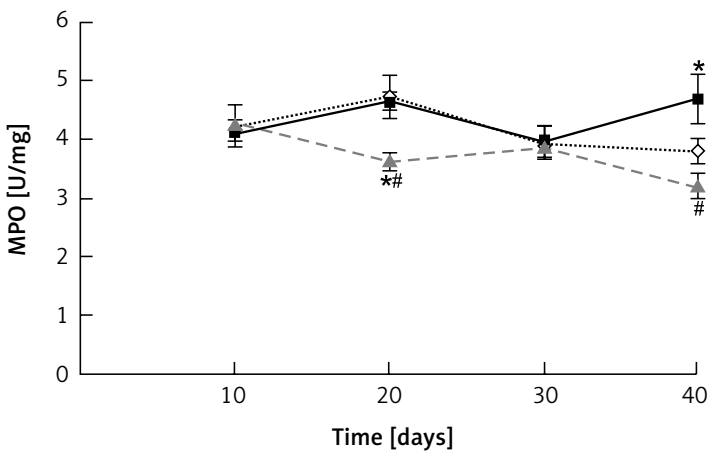

B

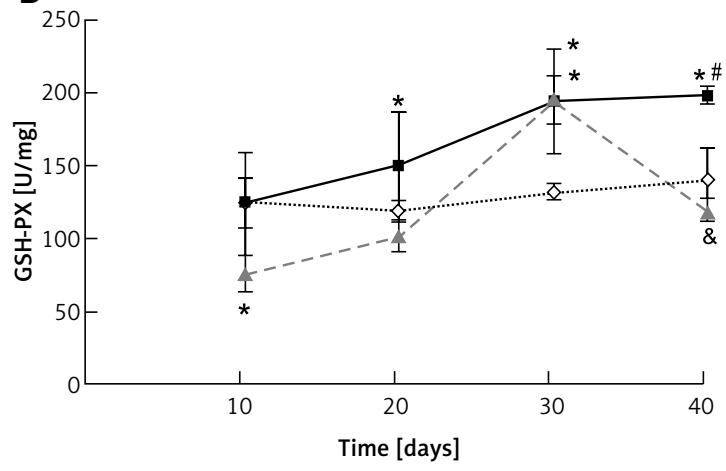

D

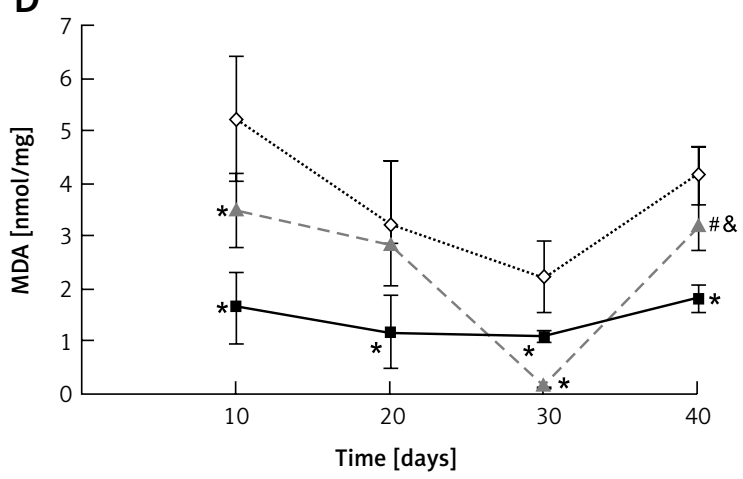

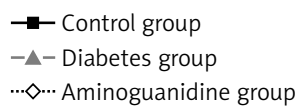

Figure 3. Content of oxidative stress factors in three groups at four different times (10 d, $20 \mathrm{~d}, 30 \mathrm{~d}, 40 \mathrm{~d})$. A - T-AOC, B - GSH-PX, C - $\mathrm{H}_{2} \mathrm{O}_{2}, \mathrm{D}-\mathrm{MDA}, \mathrm{E}-\mathrm{MPO}$

${ }^{\star} P<0.05$ vs. control group; ${ }^{*} p<0.05$ vs. aminoguanidine group; ${ }^{\&} p<0.05, I L-1 \alpha$ level on $40^{\text {th }}$ day vs. that on $30^{\text {th }}$ day.

A previous report on the induced diabetic rat model in 8 weeks stated that the thickness of the skin tissue epidermis and dermis layer of rats was significantly thinner, epidermal cell layers were unclear, part of the epidermis lacked multi-layer arrangement and the number of prickle cells was obviously reduced in the skin of diabetic rats. In addition, the dermal collagen was disorganized, degenerated or fractured, and the degeneration area of collagen presented focal infiltration of chronic inflammatory cells [25]. All the results were consistent with those observed in rats after 6 weeks of successful induction of diabetes in our study. But in the aminoguanidine group, the epidermis was slightly thickened, and the collagen and inflammatory cell infiltration were rarely normal. Thus, aminoguanidine cream can effectively alleviate the pathological changes of skin tissue in diabetes at the system level. 
As aminoguanidine has acknowledged antioxidant activity, thus, we conducted several tests to decide whether the protective effect is related to the antioxidant activity of aminoguanidine. $\mathrm{H}_{2} \mathrm{O}_{2}$ is an important indicator to assess neutrophils' oxygen-dependent bactericidal capacity, and MPO can reflect the number of neutrophils in skin tissue. It has been reported that MPO in injured skin tissue of diabetes is significantly higher than that of the control [26], which was consistent with the present results in our study. However, the content of both MPO and $\mathrm{H}_{2} \mathrm{O}_{2}$ was kept at a higher level in the diabetes group, while it was significantly lower in the aminoguanidine group at the end of the experiment. Therefore, MPO and $\mathrm{H}_{2} \mathrm{O}_{2}$ the in diabetes group may perform their bactericidal capacity during the experiment period, while in the aminoguanidine group they may be only partly activated or still in an inactive state. Thus the protective effect of aminoguanidine may not act through the function of MPO and $\mathrm{H}_{2} \mathrm{O}_{2}$. It has been indicated that neutrophils dispersed in skin tissue could be activated by AGE, and the activated neutrophils can then release $\mathrm{H}_{2} \mathrm{O}_{2}$ to damage normal tissue $[27,28]$. Furthermore, T-AOC reflects the overall cellular endogenous antioxidative capability including both enzymatic and non-enzymatic antioxidants [29], and GSH-PX is a kind of secreted selenium-dependent enzyme that can reduce hydroperoxides and organic hydroperoxides in the human body [30]. The reduction in activity of T-AOC and GSH-PX will lead to a decrease in antioxidant ability. The activity of T-AOC and GSH-PX in our study was in a state of dramatic change during the treatment period, and finally on the $40^{\text {th }}$ day the activity of aminoguanidine was tending towards stability (control group), while the T-AOC activity of the diabetes group also reached the normal level. So the lower content of $\mathrm{H}_{2} \mathrm{O}_{2}$ and higher level of GSH-PX in the aminoguanidine group compared with the diabetes group indicate that aminoguanidine interference may have an effect on inhibiting AGE generation, and further reducing the burst of neutrophils through the antioxidant capacity of GSH-PX.

Studies have shown that TNF- $\alpha$ secretion from microglia could be stimulated by high glucose condition [31-34]. Thus, the release of inflammatory cytokines in the early stage does not necessarily depend on the generation of oxidative stress. In addition, the high glucose condition may also promote the secretion of inflammatory cytokines. In this study, the contents of TNF- $\alpha$ in the diabetes group increased significantly after 30 days, but the expression level of TNF- $\alpha$ was similar to the control group in the aminoguanidine group. Therefore, the increase of TNF- $\alpha$ in skin tissue of the diabetes group may be closely related to the high glucose condition, and the increased TNF- $\alpha$ would then further lead to the increase of IL- 8 and ICAM [35], as observed in the current study. TNF- $\alpha$, IL-8 and ICAM all play important roles in regulating neutrophil migration and the inflammatory response [36]. Low content of TNF- $\alpha$, IL- 8 and ICAM in the aminoguanidine group may indicate that aminoguanidine inhibits the inflammatory response induced by diabetes. The IL-1 $\alpha$ is considered to be an important part of the skin protective barrier and is also a co-factor of other inflammatory mediators which can promote the formation of collagen, cell proliferation as well as cytokine release [37-39]. The low content of IL- $1 \alpha$ also contributes to the inhibitory effect of aminoguanidine on the inflammatory response. Therefore, aminoguanidine cream could alleviate the local inflammatory response by regulating the generation of inflammatory cytokines TNF- $\alpha$, IL-8, ICAM and IL- $1 \alpha$.

The observation by HE staining is only a simple and cursory evaluation for the damage and infiltration of immune cells. The method cannot provide the accurate number and position of infiltrating cells. Further study using a more accurate method, such as the immunofluorescence method, will be useful to discover the accurate changes in the skin tissue. Moreover, there were in total 51 rats used to evaluate the protective effect of aminoguanidine cream on the skin of diabetes rats. The sample was small, and many related indexes have not been completely studied here. In addition, MDA, as a main index of cell membrane lipid peroxidation, should be abundantly expressed in the case of AGE expression. Nevertheless, in the current study, MDA content was lower compared with the control group both in the aminoguanidine group and the diabetes group, which was puzzling. Therefore, a further study to evaluate the detailed mechanism for aminoguanidine in diabetes should be conducted with accurate examinations and a big sample, and to ensure the changes of MDA in the treatment.

In conclusion, aminoguanidine may have a good systemic effect on alleviating the pathological changes of skin tissue in diabetes rats, which may be attributed to the regulation of the antioxidant capacity of GSH-PX and the generation of inflammatory cytokines TNF- $\alpha$, IL-8, ICAM and IL- $1 \alpha$.

\section{Acknowledgments}

The author(s) disclosed receipt of the following financial support for the research, authorship, and/or publication of this article. The research was supported by the National Natural Science Foundation of China (30700871, 81272111, 81071568); Science and Technology Innovation Foundation of Shanghai Jiao Tong University School of Medicine; Translational Medical Research Institute 
Stem Cells and Regenerative Medicine Base in Shanghai Jiao Tong University School of Medicine (TS201109); Major State Basic Research Development Program of China (2012CB518105).

\section{Conflict of interest}

The authors declare no conflict of interest.

\section{References}

1. Gardner DG, Shoback DM. Greenspan's basic and clinical endocrinology. McGraw-Hill Medical New York 2007.

2. Zimmet P. Globalization, coca-colonization and the chronic disease epidemic: can the Doomsday scenario be averted? J Intern Med 2000; 247: 301-10.

3. Medina A, Scott PG, Ghahary A, Tredget EE. Pathophysiology of chronic nonhealing wounds. J Burn Care Res 2005; 26: 306-19.

4. Monastiriotis C, Papanas N, Veletza S, Maltezos E. APOE gene polymorphisms and diabetic peripheral neuropathy. Arch Med Sci 2012; 8: 583-8.

5. Varga M, Sixta B, Bem R, Matia I, Jirkovska A, Adamec M. Application of gentamicin-collagen sponge shortened wound healing time after minor amputations in diabetic patients - a prospective, randomised trial. Arch Med Sci 2014; 10: 283-7.

6. Firouzjaei MA, Jafari MR, Eskandari M, Anarkoli IJ, Alipour M. Aminoguanidine changes hippocampal expression of apoptosis-related genes, improves passive avoidance learning and memory in streptozotocin-induced diabetic rats. Cell Mol Neurobiol 2014; 34: 343-50.

7. Aiala GF, Oliveira AM, Costa FO, Fialho DL, Cunha AS Jr, Oliveira PA. Effect of local application of aminoguanidine on the biomechanical retention of implants in rats with induced diabetes. Int J Oral Maxillofac Implants 2013; 28: 1272-7.

8. E Nico ETM, de Oliveira PR, de Souza LP, et al. The action of aminoguanidine on the liver of trained diabetic rats. J Diabetes Metab Disord 2013; 12: 40.

9. Schmitt A, Hauser C, Jaunin F, Dayer JM, Saurat JH. Normal epidermis contains high amounts of natural tissue IL-1 biochemical analysis by HPLC identifies a MW approximately $17 \mathrm{Kd}$ form with a P1 5.7 and a MW approximately $30 \mathrm{Kd}$ form. Lymph Res 1986; 5: 105-18.

10. Tian M, Qing C, Niu Y, et al. Effect of aminoguanidine intervention on neutrophils in diabetes inflammatory cells wound healing. Exp Clin Endocrinol Diabetes 2013; 121: 635-42.

11. Lapolla A, Traldi P, Fedele D. Importance of measuring products of non-enzymatic glycation of proteins. Clin Biochem 2005; 38: 103-15.

12. Singh R, Barden A, Mori T, Beilin L. Advanced glycation end-products: a review. Diabetologia 2001; 44: 129-46.

13. Ahmed N. Advanced glycation endproducts - role in pathology of diabetic complications. Diabetes Res Clin Practice 2005; 67: 3-21.

14. Meerwaldt R, Links TP, Graaff R, et al. Increased accumulation of skin advanced glycation end-products precedes and correlates with clinical manifestation of diabetic neuropathy. Diabetologia 2005; 48: 1637-44.

15. Goova MT, Li J, Kislinger T, et al. Blockade of receptor for advanced glycation end-products restores effective wound healing in diabetic mice. Am J Pathol 2001; 159: 513-25.
16. Corbett JA, et al. Aminoguanidine, a novel inhibitor of nitric oxide formation, prevents diabetic vascular dysfunction. Diabetes 1992; 41: 552-6.

17. Hammes HP, Martin S, Federlin K, Geisen K, Brownlee M. Aminoguanidine treatment inhibits the development of experimental diabetic retinopathy. Proc Natl Acad Sci USA 1991; 88: 11555-8.

18. Ozturk A, Fırat C, Parlakpınar H, Bay-Karabulut A, Kirimlioglu H, Gurlek A. Beneficial effects of aminoguanidine on skin flap survival in diabetic rats. Exp Diabetes Res 2012; 2012: 721256

19. Stetten D, Welt ID, Ingle DJ, Morley EH. Rates of glucose production and oxidation in normal and diabetic rats. J Biol Chem 1951; 192: 817-30.

20. Aslan M, Deliorman Orhan D, Orhan N, Sezik E, Yesilada E. In vivo antidiabetic and antioxidant potential of Helichrysum plicatum ssp. plicatum capitulums in streptozotocin-induced-diabetic rats. J Ethnopharmacol 2007; 109: 54-9.

21. Vats V, Yadav S, Grover J. Ethanolic extract of Ocimum sanctum leaves partially attenuates streptozotocin-induced alterations in glycogen content and carbohydrate metabolism in rats. J Ethnopharmacol 2004; 90: 155-60.

22. Stadler K, Bonini MG, Dallas S, et al. Involvement of inducible nitric oxide synthase in hydroxyl radical-mediated lipid peroxidation in streptozotocin-induced diabetes. Free Radic Biol Med 2008; 45: 866-74.

23. Achar RAN, Silva TC, Achar E, Martines RB, Machado JLM. Use of insulin-like growth factor in the healing of open wounds in diabetic and non-diabetic rats. Acta Cirurgica Brasileira 2014; 29: 125-31.

24. Peppa M, Stavroulakis P, Raptis SA. Advanced glycoxidation products and impaired diabetic wound healing. Wound Repair Regen 2009; 17: 461-72.

25. Panagiotopoulos S, O'Brien RC, Bucala R, Cooper ME, Jerums $G$. Aminoguanidine has an anti-atherogenic effect in the cholesterol-fed rabbit. Atherosclerosis 1998; 136: 125-31.

26. Berns KI, Linden RM. The cryptic life style of adeno-associated virus. Bioessays 1995; 17: 237-45.

27. Anderson MM, Hazen SL, Hsu FF, Heinecke JW. Human neutrophils employ the myeloperoxidase-hydrogen peroxide-chloride system to convert hydroxy-amino acids into glycolaldehyde, 2-hydroxypropanal, and acrolein. A mechanism for the generation of highly reactive alpha-hydroxy and alpha, beta-unsaturated aldehydes by phagocytes at sites of inflammation. J Clin Investig 1997; 99: 424.

28. Cronstein BN, Kubersky SM, Weissmann G, Hirschhorn R. Engagement of adenosine receptors inhibits hydrogen peroxide ( $\left.\mathrm{H}_{2} \mathrm{O} 2\right)$ release by activated human neutrophils. Clin Immunol Immunopathol 1987; 42: 76-85.

29. Wei X, Liu H, Sun X, et al. Hydroxysafflor yellow A protects rat brains against ischemia-reperfusion injury by antioxidant action. Neurosci Lett 2005; 386: 58-62.

30. Kingsley PD, Whitin JC, Cohen HJ, Palis J. Developmental expression of extracellular glutathione peroxidase suggests antioxidant roles in deciduum, visceral yolk sac, and skin. Mol Reprod Develop 1998; 49: 343-55.

31. Duraisamy Y, Slevin M, Smith N, et al. Effect of glycation on basic fibroblast growth factor induced angiogenesis and activation of associated signal transduction pathways in vascular endothelial cells: possible relevance to wound healing in diabetes. Angiogenesis 2001; 4: 277-88.

32. Facchiano F, Lentini A, Fogliano V, et al. Sugar-induced modification of fibroblast growth factor 2 reduces its angiogenic activity in vivo. Am J Pathol 2002; 161: 531-41. 
33. Kirstein $M$, et al. Advanced protein glycosylation induces transendothelial human monocyte chemotaxis and secretion of platelet-derived growth factor: role in vascular disease of diabetes and aging. Proc Natl Acad Sci USA 1990; 87: 9010-4.

34. Quan Y, Jiang CT, Xue B, Zhu SG, Wang X. High glucose stimulates TNFalpha and MCP-1 expression in rat microglia via ROS and NF-kappaB pathways. Acta Pharmacol Sinica 2011; 32: 188-93.

35. Salva PS, Doyle NA, Graham L, Eigen H, Doerschuk CM. TNF-alpha, IL-8, soluble ICAM-1, and neutrophils in sputum of cystic fibrosis patients. Pediatr Pulmonol 1996; 21: 11-9.

36. Yang L, Froio RM, Sciuto TE, Dvorak AM, Alon R, Luscinskas FW. ICAM-1 regulates neutrophil adhesion and transcellular migration of TNF-alpha-activated vascular endothelium under flow. Blood 2005; 106: 584-92.

37. Keel M, Schregenberger N, Steckholzer U, et al. Endotoxin tolerance after severe injury and its regulatory mechanisms. J Trauma 1996; 41: 430-7.

38. Pape HC, van Griensven M, Rice J, et al. Major secondary surgery in blunt trauma patients and perioperative cytokine liberation: determination of the clinical relevance of biochemical markers. J Trauma 2001; 50: 989-1000.

39. Gahring LC, Buckley A, Daynes RA. Presence of epidermal-derived thymocyte activating factor/interleukin 1 in normal human stratum corneum. J Clin Investig 1985; 76: 1585-91. 